\title{
KNOWLEDGE WORK Difficulty FACTORS: AN EMPIRICAL STUDY BASED ON DIFFERENT GROUPS OF KNOWLEDGE WORKERS
}

Jalil Heidary Dahooie, Abbas Afrazeh, and Seyed Mohammad Moathar Hosseini

Department of Industrial Engineering \& Management Systems, Amirkabir University of Technology, Iran

Mohammad Reza Ghezel Arsalan

Department of Industrial Engineering, University of Tehran, Iran

Accepted: December 2011

\begin{abstract}
The determination of the difficulty factor in knowledge work can be important for improving the performance of knowledge workers. In this article a regression model for investigating the difficulty of knowledge based activities (KBAs) is proposed. Four factors are considered in the model: Uncertainty, Variability of information, Amount of information and Level of skill and expertise. An empirical study based on 119 jobs from three different groups of knowledge workers (i.e. managerial, professional and clerical) shows that there are significant differences between the difficulty of the KBAs in managerial, clerical and professional jobs, and that managerial KBAs are more difficult than the KBAs of the other two groups. Furthermore, regression models indicate that Level of skill and expertise is the most influential factor in the difficulty of the KBAs in each of the three groups.
\end{abstract}

Key words: knowledge work, difficulty index, knowledge based activities (KBAs), variability of information, amount of information, uncertainty, level of skill and expertise

JEL: I24, C12

\section{1}

\section{Introduction}

The business environment today consists of a knowledge-based economy. In this economy, knowledge work (KW) and knowledge workers (KWrs) are one of the main resources for the preservation and preferment of a firm's competencies (Lavoie, Roy \& Therrien, and 2003:832), so it is important to improve the performance of knowledge workers.

Drucker states that:

"The most important, and indeed the truly unique, contribution of management in the 20th century was the fifty-fold increase in the productivity of the manual worker in manufacturing. The most important contribution management needs to make in the 21st century is similarly to increase the productivity of knowledge work and knowledge workes" (Peter Drucker, 1999:79).

Fritz Machl and Peter F. Drucker were the first people to define the knowledge work concept (Cortada, 1998:16; Okkonen, 2003:55; Pyoria, 2005:116). Drucker (1959) described special workers as Knowledge workers and introduced them as people who apply knowledge to work, rather than manual skill and muscle (Nickols, 2000:1). Since then, knowledge work has been one of the main focus points of research. The reason is the growing population of knowledge workers in today's business environment. The number and proportion of knowledge workers are increasing rapidly in comparison with those of manual workers (Drucker, 1999:80; Nickols, 2000:1; Ramirez \& Steudel, 2008:564).

Several definitions have been presented in the literature, provided definitions of $\mathrm{KW}$ and $\mathrm{KWrs}$. But in most of the cases, they are so different that no consensus is reached (Guns \& Valikangas, 1998; Pyoria, 2005; Shi-You, 2008; Heidary et al., 2011).

Heidary et al. (2011) examined 70 definitions of $\mathrm{KW}$ and 82 definitions of $\mathrm{KWr}$ and 
classified them in two main paradigms and four streams. They assumed knowledge work as a continuum and defined it as a job which is comprised of knowledge based activities (KBAs) and tasks. Finally, they proposed a framework for quantitative definition and segmentation of knowledge works (Heidary et al., 2011).

Therefore, in this article, we define knowledge work as a job that consists of working with knowledge and performing activities like knowledge and information creation, finding, development and use (Drucker, 1993; Hammer, Leonard \& Davenport, 2004:17; Davenport, 2005:28; Turner \& D’Art, 2008:703).

As knowledge work is a cognitive process, the main characteristic of knowledge work is not the quantity, because quality is more important and difficulty is the key index of quality (Drucker, 1999; Cao \& Li, 2008:1).

The main purpose of this article is to propose a model for determining the factors influencing the difficulty of KBAs. Empirical research shows there are significant differences between the difficulty of jobs in managerial, clerical and professional KBAs. For this reason it is appropriate to model each group separately. Three regression models are applied, based on four factors: Uncertainty, Variability of information, Amount of information and Level of skill and expertise.

We define different types of knowledge work tasks and activities, and then propose a method for calculating the difficulty index (DI) of knowledge based activities. Following that, we compare the difficulty index for the knowledge based activities (KBAs) of three different groups of knowledge workers (managers, professionals and clerks). Data for the analysis were obtained from 119 jobs in 11 organisations and the data are analysed by ANOVA. Finally, regression models for investigating the difficulty of KBAs are proposed, based on the four job characteristics: Uncertainty, Level of skill and expertise, Variability of information and Amount of information.

The rest of this paper is organised as follows: Section 2 reviews, in the literature, definitions of work complexity and difficulty. Section 3 defines suitable levels for measuring work difficulty. Section 4 defines knowledge work tasks and explains different activity types. Sections 5-7 discuss a methodology for calculating the difficulty index of KBAs in different types of knowledge work. Empirical study and the results of ANOVA and Regression models will be given in Sections 8-10. The results will be discussed in Section 11. Finally, in Section 12 we draw conclusions and outline future research.

\section{2}

\section{Literature review}

The difficulty of knowledge work is one of the most important attributes of knowledge work that is investigated by academics and practitioners. If we compute the process difficulty of knowledge work, it could further improve the efficiency of the knowledge work (Cao \& Li, 2008:1). This number can be used for effective management of knowledge workers. For example, this index can be used in training systems for education priority or in job design for determining important tasks that form each job.

Thomas \& Baron used the complexity index as one of the knowledge work components, and they drew an Expected Graph Area of Knowledge Work based on this component. They defined complexity as the difficulty of the job. They said, 'This component involves the number and difficulty of decisions, and the amount of knowledge that is needed' (Thomas \& Baron, 1994:10).

Davenport used complexity of knowledge work as a dimension for presenting a classification structure for knowledge-intensive processes, and proposed managerial solutions for improving productivity of each category of knowledge worker. He defined complexity as the interpretation and judgment required in the process (Davenport, 2005:27).

The purpose of Lee's $\mathrm{PhD}$ thesis was to explore the perceived job change in four dimensions of knowledge work (information input, mental process, work output, and interaction with others) among frontline employees, middle managers, and senior managers in a large Korean bank. His study examined the perceived levels of importance, frequency, and difficulty for each of the four dimensions of knowledge work performed three years ago. He said that 'difficulty of the job activities is the degree of difficulty to learn the work activity in order to perform successfully' (Lee, 2005:59). 
Ramírez and Steudel used complexity as one of eight measures for quantification of knowledge work. They define complexity as the degree to which a task offers great difficulty in understanding or has confusing interrelated sub-tasks (Ramirez \& Steudel, 2008).

In addition, articles in psychology, medicine, management, etc. use task complexity and difficulty as important dimensions in their analysis, and they discuss their effects (Huber, 1985; Harkins \& Petty, 1982; Veltman \& Gaillard, 1998; Philiastides, Ratcliff \& Sajda, 2006), but few try to quantify this concept.

The main research for identification of task complexity was done by Cao and Li (2008). Based on 188 questionnaires and confirmatory factor analysis, they show that the process difficulty of knowledge work was influence by four factors: complexity, uncertainty, structure and ambiguity (Cao \& Li, 2008).

\section{3}

\section{What is an appropriate level for measuring difficulty?}

The measurement of knowledge work difficulty at job level is very complex. Conducting measurement at lower levels of a job (i.e. subprocesses and activities) is more practical (Thomas \& Baron, 1994:14). We must therefore select an appropriate order of work unit for measuring job difficulty. Although there is no solid agreement about the taxonomy of work, each perspective is somewhat similar (Lee, 2005:36).

Denise Ford Jackson examines the structure offered by Mundel (Mundel, 1983:34) and reached the conclusion that this structure is not applicable for knowledge work, because knowledge work rarely results in a physical product. She recommended a structure which was more applicable for describing knowledge work (Jackson, 1989:50). Table 1 presents her recommended structure.

Norton (2003) described taxonomy of work with four levels: job, duty, task and step, which are shown in Figure 1 (Lee, 2005:36).

Brannick and Levine (2002) described a work taxonomy in more detail as is shown in Table 2 (Lee, 2005:36). As these levels are pro-portionate with most job analysis methods, this taxonomy seems to be suitable for our objectives in this article.

With respect to these levels, we select the

Table 1

Orders of work units (Jackson, 1989:50)

\begin{tabular}{|l|l|l|}
\hline \multicolumn{1}{|c|}{ Numerical designation } & \multicolumn{1}{|c|}{ Output name } & \multicolumn{1}{c|}{ Definition } \\
\hline $8^{\text {th }}$ order work-unit & Global end & What is achieved because of the outputs of all activities \\
\hline $7^{\text {th }}$ order work-unit & Intermediate goal & The achievement of strategic goal components by a division \\
\hline $6^{\text {th }}$ order work-unit & Program & The achievement of tactical goals by an Organisation \\
\hline $5^{\text {th }}$ order work-unit & Mission & The achievement or output of a work group \\
\hline $4^{\text {th }}$ order work-unit & Job & The achievement of part of the end result by an individual \\
\hline $3^{\text {th }}$ order work-unit & Task & A natural unit of a job \\
\hline $2^{\text {th }}$ order work-unit & Element & Functional unit of a task \\
\hline $1^{\text {th }}$ order work-unit & Behavior & The performance of a human behavior (physical or mental) \\
\hline
\end{tabular}

activity level for determining the difficulty index of the knowledge work. The next section defines knowledge work tasks and activities.

\section{4}

\section{Knowledge work tasks and activities}

Knowledge work is, to a great extent, selfmanaged. The knowledge worker is expected to know how to organise and manage his/her work. He/she is also expected to have knowledge or know where to find it. This means a knowledge worker has three types of tasks (Davis, 2002: 68).

Job-specific tasks: what the workers are working on for the organisation. Examples of these tasks include preparing a budget, planning and scheduling a project, eliciting and documenting system requirements, and writing application software.

Knowledge building and maintenance tasks: 
Figure 1

Taxonomy of work - job, duty, and task (Lee, 2005)

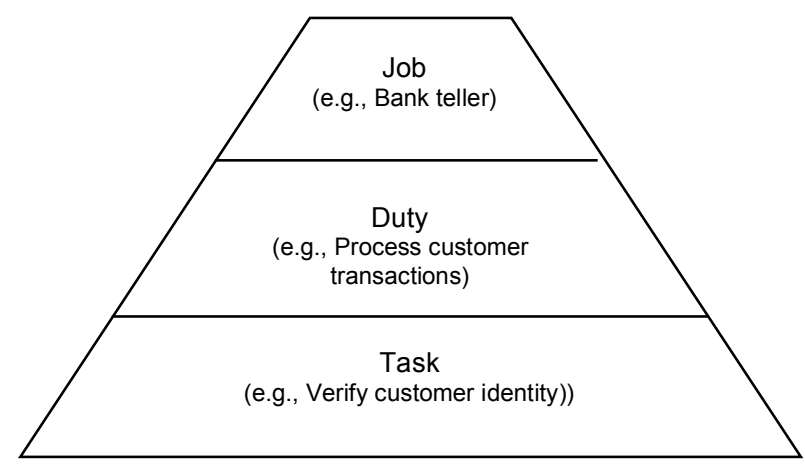

Table 2

Various units of job analysis (Lee, 2005: 36)

\begin{tabular}{|l|l|}
\hline \multicolumn{1}{|c|}{ Unit of Analysis } & \multicolumn{1}{c|}{ Example } \\
\hline Organisation & ABC Electronics \\
\hline Division & Service \\
\hline Department & Human Resources \\
\hline Job & HRD Consultant \\
\hline Position & Chan Lee, Assistant Manager \\
\hline Duty & Manage employment process \\
\hline Task & Conduct job offer process \\
\hline Activity & Call successful job applicants \\
\hline Step & Pick up the phone \\
\hline
\end{tabular}

these are tasks that create value in knowledge workers and maintain existing knowledge. Some examples of these tasks are scanning and reading professional literature, attending professional meetings, learning new technologies, and building a network of colleagues.

Work management tasks: these tasks help knowledge workers to manage knowledge work to achieve effective results using time and mental resources efficiently. These tasks include the following: maintaining work motivation; maintaining readiness to work, plan, sequence, and schedule activities; and managing collaboration.

Furthermore, each of these tasks can have three types of activities: knowledge based activities (KBAs), communication based activities (CBAs), and supplementary activities (Davis, 2001:14-16). This means that the main activities of each task are usually knowledge based (like getting information, analysing data or information, and thinking creatively).

Although knowledge work can be done individually, it is often done in teams or by interacting with others. Activities like assisting and caring for others, selling or influencing others, training and teaching others, and staffing organisational units can be classified in this category.

In addition, knowledge workers sometimes do some supplementary activities. This group constitutes activities like typing reports, archiving documents, and physical activities. There are three reasons for performing these activity types: 1) it is more efficient to do the supplementary activities as part of the knowledge work; 2) the time performing these activities may be a form of rest for a knowledge worker; 3 ) the organisation does not provide support for these activities (Davis, 2001:14-16).

Figure 2 shows knowledge work tasks and the relationships between them and different types of knowledge work activities.

Knowledge based activity (KBA) is the main focus of this article; for determining this 
activity, a literature review was conducted and 66 definitions of knowledge work and 80 definitions of knowledge workers were gathered by reviewing existing references up to 2010 . Then, knowledge work activities were extracted from these definitions. Since this list was not complete, activities extracted from definitions were then matched with O*NET (National center for $\mathrm{O}^{*} \mathrm{NET}$ development, 2010) generalised work activities. This analysis determined the final list of knowledge based activities (see Appendix 1).

Figure 2

General model of knowledge work

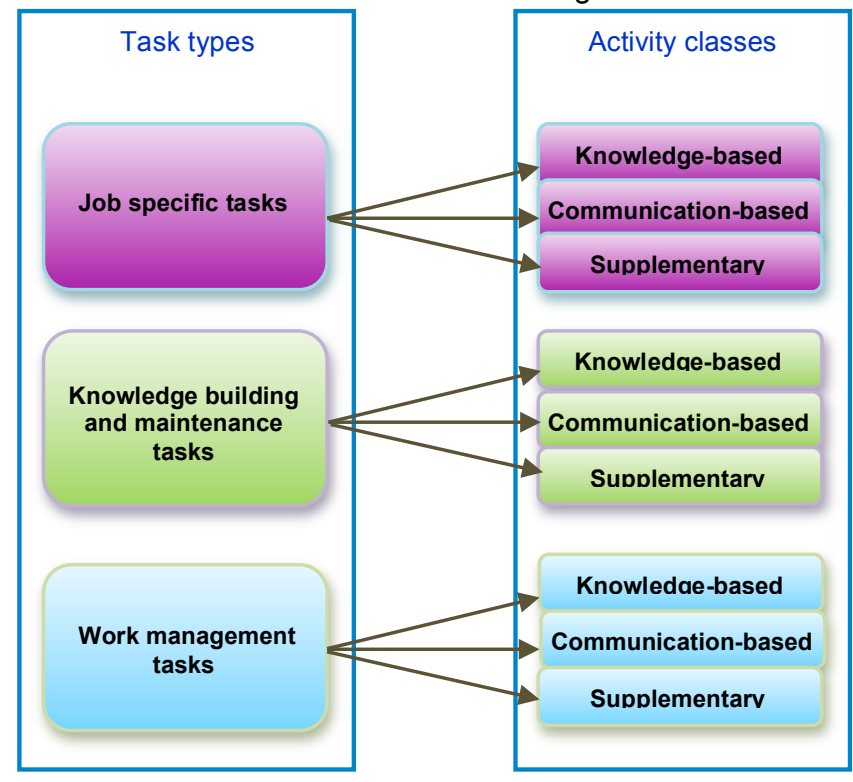

5

\section{Measuring difficulty of KBAs}

Although all activities in the knowledge based category (Appendix 1) are knowledge intensive, they differ in difficulty. These differences can be derived from two factors:

- Complexity weight: Firstly, each activity does not have the inherent equal difficulty that the others have. For example 'getting information' and 'Thinking Creatively' are both knowledge based activities, but they have different degrees of difficulty. This means each KBA has an inherent weight of difficulty.

- Level of difficulty: Secondly, each activity has different difficulty levels in itself. For example, the difficulty of 'making decisions and solving problems' can differ between 'determining the meal selection from a cafeteria' and 'making the final decision about a company's five-year plan'.
Each of these two factors mentioned above will now be investigated further.

\section{Measuring complexity weight}

Knowledge based activities have different degrees of complexity and these differences must be considered for accurately determining difficulty.

We have considered worker functions that are defined in the Dictionary of Occupational Title (DOT), as complexity weights for each activity type (Jackson, 1989; Fine, Harvey \& Cronshaw, 2004).

The worker functions are based on the premise that every job requires a worker to perform in some degree with data, people and things, and that the involvement with each of these can be expressed as a hierarchy (Jackson, 1989: 55; Fine, Harvey \& Cronshaw, 2004).

The functions are ordered within each category from the most complex to the simplest, in increasing number. Thus function order 1 is more complex than function order 6 
in each category (see Table 3 ).

For assigning weight to each KBA based on worker function, we used an extended table of worker function which was developed by Denise Ford Jackson (Jackson, 1989:55). For each KBA, a proportionate worker function was found and, based on this worker function, a weight was assigned to the KBA (Weight 7 for $\mathrm{d} 0$ and 1 for $\mathrm{d} 6$ ).

\section{Measuring level of difficulty}

For measuring the level of difficulty of activities, the $\mathrm{O}^{*} \mathrm{Net}$ standard of activity level was used. In this standard, the difficulty level of each activity can vary from 1 to 7 , and for directing the determination of this level, three

Table 3

DOT worker functions (Jackson, 1989:55)

\begin{tabular}{|c|c|c|}
\hline $4^{\text {th }}$ Digit data (D) & $5^{\text {th }}$ Digit people $(P)$ & $6^{\text {Th }}$ Digit things $(T)$ \\
\hline $\begin{array}{l}0 \text { Synthesising } \\
1 \text { Coordinating } \\
2 \text { Analysing } \\
3 \text { Compiling } \\
4 \text { Computing } \\
5 \text { Copying } \\
6 \text { Comparing }\end{array}$ & $\begin{array}{l}0 \text { Mentoring } \\
1 \text { Negotiating } \\
2 \text { Instructing } \\
3 \text { Supervising } \\
4 \text { Diverting } \\
5 \text { Persuading } \\
6 \text { Speaking / signaling } \\
7 \text { Serving } \\
8 \text { Helping / taking instruction }\end{array}$ & $\begin{array}{l}0 \text { Setting Up } \\
1 \text { Precision working } \\
2 \text { Operating / controlling } \\
3 \text { Driving / operating } \\
4 \text { Manipulating } \\
5 \text { Tending } \\
6 \text { Feeding / off bearing } \\
7 \text { Handling }\end{array}$ \\
\hline
\end{tabular}

examples (anchors) were put in this interval. In Figure 3 this standard showed for the activity 'getting information'. Anchors of this activity are 'follow a standard blueprint', 'review a budget' and 'study international tax laws'.
To decide the difficulty level of a specific activity for a specific job, subject matter experts (SMEs) like knowledge workers were asked, 'What level of the activity is needed in his/her job tasks?'

Figure 3

Determining the activity level in each task (getting information)

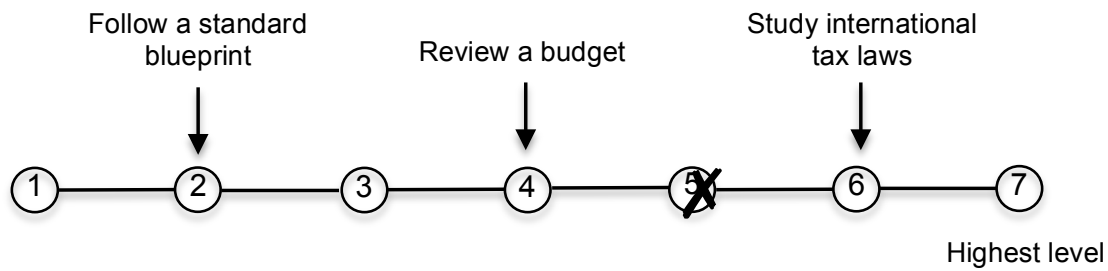

As illustrated in the above example, it is important to note that the anchors of the level scale are unique for each activity.

\section{Calculating the difficulty index (DI)}

According to the two parameters mentioned above, we define the difficulty index (DI) of an activity as follows:

$$
\mathrm{DI}=\mathrm{CI} \text { x LI }
$$

CI: Complexity weight of the activity

LI: Level of difficulty of the activity

The difficulty index (DI) is a number between
1 and 49. An activity can have a difficulty index of 49 only if it has a complexity weight equal to 7 (the worker function must be 6 in the data) and the difficulty level index must also be equal to 7 .

\section{6}

\section{Identifying factors influencing difficulty}

Identification of factors that affect the difficulty of KBAs can be worthwhile for dealing with different issues in knowledge 
work, like productivity and training needs assessment. A comprehensive literature review was conducted and the following four factors were elicited:

- Variability of information: this factor shows the similarity of information that knowledge workers use for changing it to knowledge (Hashemian Bojnord \& Afrazeh, 2006:3407).

- Amount of information: this factor shows the amount of information that the knowledge workers manipulate (Hashemian Bojnord \& Afrazeh, 2006:3407).

- Uncertainty: this factor is frequently defined as a knowledge inadequacy which may arise from several sources. The result of uncertainty may be the individual's inability to predict correctly and hesitating to make the decision (Cao \& Li, 2008:2).

- Level of skill and expertise: This shows the level of skill and expertise that is needed for changing information to knowledge and performing each task (Pan, Liu \& Hawryszkiewycz, 2008:47).

\section{7}

\section{Comparing the difficulty index between different groups of knowledge work}

As Davenport et al. (2002) mentioned, 'Our first conviction is that it is a mistake to lump all knowledge workers into one category'. Not all knowledge workers are alike and they need to be segmented (Hammer et al., 2004:17). Researchers use different approaches for the categorisation of knowledge workers. For example, they may be categorised according to the level of responsibility they have in the company. (Thomas \& Baron, 1994; Dove, 1998; Iivari \& Linger, 1999:7; Davenport, 2002:4; Davenport, 2005:27; Hampson \& Junor, 2005: 169).

To gain more reliable results in this research, we also need segmentation of knowledge work. In considering the practical point of view, knowledge workers were divided into three broad categories: managers, defined as workers with supervisory or coordination roles; professionals, defined as workers in charge of specialised activities; and clerks, defined as workers in charge of administrative support activities (Francalanci \& Galal, 1998: 230; Coates, 1986:7). However, some researchers believe that professional and clerical attributes are the same and then categorise knowledge workers in two categories: managerial and non managerial workers (Leigh, 1984).

Some research has been done for determining differences between these groups of workers. For example, Francalanci and Galal test the effect of an increase in IT investment on the productivity of each of these three groups (Francalanci \& Galal, 1998). Lee explores the perceived job change toward dimensions of knowledge work among frontline employees, middle managers, and senior managers in a large Korean bank (Lee, 2005).

In this article, we want to test differences between the difficulty index (DI) of these three classes of knowledge workers. Thus, the following hypothesis concerning DI was generated:

HO = difference of difficulty index between different groups is not significant

$H 1$ = otherwise (difference of difficulty index between different groups is significant)

Based on this hypothesis, if $\mathrm{H} 0$ is rejected, we shall develop a specific regression model for each of the three groups of knowledge work.

\section{8}

\section{Methodology}

In this part of the article we want to introduce our research methodology. The steps of the methodology are as follows (Figure 4).

\section{Selecting knowledge work jobs}

In the first step we had to select some knowledge work jobs for analysis. As there is no exact method for identification of knowledge work types, we selected some jobs from the literature review that were mentioned as knowledge workers (engineers, researchers, etc.). In this step, 119 jobs in 11 organisations were selected in our empirical study. The sample profile is given in Table 4.

\section{Identifying the KBAs of each task}

For identifying KBAs we first needed to determine the tasks of each job. Tasks are the main part of the job description, so we tried to gather descriptions of the 119 jobs mentioned above. If a description of a job didn't exit, we would have implemented job analysis to elicit 


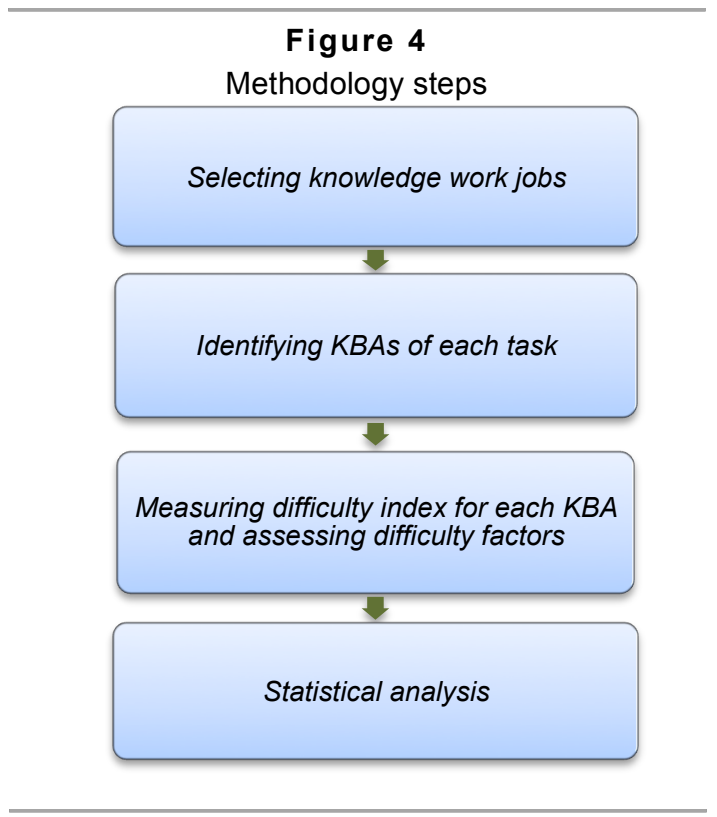

Table 4

Sample profile of selected jobs

\begin{tabular}{|c|c|c|c|c|}
\hline \multirow{2}{*}{ Organisation ID } & Managerial & Professional & Clerical & $\begin{array}{c}\text { Total jobs in each } \\
\text { organisation }\end{array}$ \\
\hline $\mathbf{1}$ & 3 & 5 & 2 & 10 \\
\hline $\mathbf{2}$ & 2 & 4 & 4 & 10 \\
\hline $\mathbf{3}$ & 3 & 5 & 2 & 10 \\
\hline $\mathbf{4}$ & 1 & 3 & 6 & $\mathbf{1 0}$ \\
\hline $\mathbf{5}$ & 5 & 5 & 0 & $\mathbf{1 0}$ \\
\hline $\mathbf{6}$ & 10 & 4 & 6 & $\mathbf{2 0}$ \\
\hline $\mathbf{7}$ & 3 & 4 & 7 & $\mathbf{1 4}$ \\
\hline $\mathbf{8}$ & 4 & 3 & 3 & $\mathbf{1 0}$ \\
\hline $\mathbf{9}$ & 0 & 5 & 0 & $\mathbf{5}$ \\
\hline $\mathbf{1 0}$ & 0 & 10 & 0 & $\mathbf{1 0}$ \\
\hline $\mathbf{1 1}$ & 3 & 3 & 4 & $\mathbf{1 0}$ \\
\hline Total & $\mathbf{3 4}$ & $\mathbf{5 1}$ & $\mathbf{3 4}$ & $\mathbf{1 1 9}$ \\
\hline
\end{tabular}

tasks (like functional job analysis (FJA) or the Hay method). In this step KBAs which comprise each task were extracted. As discussed in Part 4, we developed extensive lists of KBAs (Appendix 1) for identifying them in each task. For this reason, subject matter experts (SMEs) in each job were interviewed and KBAs of each task were elicited.

\section{Measuring difficulty index for each $K B A$ and assessing difficulty factors}

For assessing difficulty factors for each KBA, a questionnaire was developed and a trained team were the custodians of data collection.
Detailed requested data are listed below:

- Activity level

- Uncertainty for each activity $\left(\mathrm{X}_{1}\right)$

- Level of skill and expertise for each activity $\left(\mathrm{X}_{2}\right)$

- Variability of information for each activity $\left(\mathrm{X}_{3}\right)$

- Amount of information for each activity $\left(\mathrm{X}_{4}\right)$

Based on the method described in Section 5 for the determination of each activity level, each SME needed to determine the levels of their KBAs. 
Furthermore, each SME was required to estimate four difficulty factors $\left(\mathrm{X}_{1}\right.$ to $\left.\mathrm{X}_{4}\right)$ for each of the knowledge-based activities (KBA), considering his/her job. Each factor could be given an ordinal score between 1 and 9 .

Following that, complexity weights were extracted, based on the approach described in Section (5), using worker functions. Finally, the difficulty index (DI) for each KBA was calculated by formula (1).

\section{9}

\section{Statistical analysis}

Descriptive results of the research data are reported in Table 5. As this table shows, there are more knowledge based activities for managerial jobs than there are for the other two groups $(\mathrm{N}=3581)$.

Table 5 shows that there are fewer managerial jobs in our sample than professional jobs, and that there are the same number of clerical jobs (number of managerial jobs $=34$ ). The data showed that managers may, on average, be required to perform more knowledge-based activities in performing their tasks than either professional or clerical workers do.

Table 5 also shows the mean of the DI for each group. The Difficulty index (DI) for clerical KBAs varies between 4 and 42 and their mean is equal to 18.92 (Max DI $=49)$. However, managerial and professional knowledge based activities change between 2 and 49 and their mean is equal to 24.2 and 23.2, respectively.

For testing differences between the DI of

Table 5

Data description for three job categories

\begin{tabular}{|c|c|c|c|c|c|c|c|c|}
\hline \multirow{2}{*}{$\begin{array}{c}\text { Job } \\
\text { categories }\end{array}$} & \multirow[b]{2}{*}{$\mathbf{N}$} & \multirow[b]{2}{*}{ Mean } & \multirow{2}{*}{$\begin{array}{c}\text { Std. } \\
\text { deviation }\end{array}$} & \multirow[b]{2}{*}{ Std. Error } & \multicolumn{2}{|c|}{$\begin{array}{l}95 \% \text { Confidence Interval } \\
\text { for mean }\end{array}$} & \multirow[b]{2}{*}{ Minimum } & \multirow[b]{2}{*}{ Maximum } \\
\hline & & & & & Lower bound & Upper bound & & \\
\hline Clerical & 814 & 18.9251 & 9.12887 & .31997 & 18.2970 & 19.5531 & 4.00 & 42.00 \\
\hline Professional & 3466 & 23.2121 & 10.15682 & .17252 & 22.8738 & 23.5503 & 2.00 & 49.00 \\
\hline Managerial & 3581 & 24.2016 & 8.65142 & .14457 & 23.9182 & 24.4851 & 2.00 & 49.00 \\
\hline Total & 7861 & 23.2189 & 9.51512 & 10732 & 23.0086 & 23.4293 & 2.00 & 49.00 \\
\hline
\end{tabular}

knowledge based activities (KBAs) in these three groups, we use one-way analysis of variance (ANOVA). The results are reported in Table 6. With respect to results, as sig $=000$, then the difference between groups is signifi- cant and $\mathrm{H} 0$ is rejected. We can conclude that there are differences between the DI of knowledge based activities in these three groups.

The ANOVA table does not show details of difference between these three groups of

Table 6

One-way analysis of variance (ANOVA) results

\begin{tabular}{|l|c|c|c|c|c|}
\hline \multicolumn{1}{|c|}{ Difficulty index (DI) } & Sum of squares & df & Mean square & F & Sig. \\
\hline Between groups & 18466.228 & 2 & 9233.114 & 104.671 & .000 \\
\hline Within groups & 693157.995 & 7858 & 88.210 & & \\
\hline Total & 711624.223 & 7860 & & & \\
\hline
\end{tabular}

knowledge workers. For recognising these differences, multiple range tests like Duncan are used.

As Table 7 shows, Duncan's multiple range test indicates that each one of these three groups is classified in one distinct category.
This indicates that there are significant differences between managerial jobs, clerical jobs and professional jobs in difficulty index, and managerial knowledge based activities (KBAs) are more difficult than those in the other two groups. 
Table 7

Duncan test results for difficulty index (DI)

\begin{tabular}{|l|c|c|c|c|}
\multicolumn{1}{|c|}{ Type } & \multicolumn{3}{c|}{ Subset for alpha $=\mathbf{0 . 0 5}$} \\
\hline Clerical & N & $\mathbf{1}$ & $\mathbf{2}$ & $\mathbf{3}$ \\
\hline Professional & 814 & 18.9251 & & \\
\hline Managerial & 3466 & & 23.2121 & 24.2016 \\
\hline Sig. & 3581 & & & 1.000 \\
\hline
\end{tabular}

10

\section{Fitted regression models}

For analysing the effect of independent variables $\left(\mathrm{X}_{1}\right.$ : Uncertainty; $\mathrm{X}_{2}$ : Level of skill and expertise; $\mathrm{X}_{3}$ : Variability of information; and $\mathrm{X}_{4}$ : Amount of information) on the dependent variable (difficulty index, DI) the following regression model is considered: $\hat{y}=\beta_{0}+\beta_{1} X_{1}+\beta_{2} X_{2}+\beta_{3} X_{3}+\beta_{4} X_{4}$

As regards the difference between difficulty indexes of our three groups of knowledge workers, we must examine one different linear regression for each one.

The analysis of variance for this model is summarised in Tables 8-10. The F-test for overall regression is significant for all of the

\section{Table 8}

One-way analysis of variance (ANOVA) for managerial jobs

\begin{tabular}{|l|c|c|c|c|c|c|}
\hline & \multicolumn{5}{|c|}{ ANOVA } \\
\hline 1 Model & Sum of squares & df & Mean square & F & Sig. \\
\hline Regression & 2066012 & 4 & 516503.093 & 6170.829 & .000 \\
\hline Residual & 299397.6 & 3577 & 83.701 & & \\
\hline
\end{tabular}

Table 9

One-way analysis of variance (ANOVA) for professional jobs

\begin{tabular}{|l|c|c|c|c|c|c|}
\hline & \multicolumn{5}{|c|}{ ANOVA } \\
\hline 1 & Model & Sum of squares & df & Mean square & F & Sig. \\
\hline & Regression & 1802125 & 4 & 450531.347 & 4310.195 & .000 \\
\hline Residual & 353823.6 & 3385 & 104.527 & & \\
\hline Total & 2155949 & 3389 & & & \\
\hline
\end{tabular}

Table 10

One-way analysis of variance (ANOVA) for clerical jobs

\begin{tabular}{|l|c|c|c|c|c|c|}
\hline \multicolumn{1}{|c|}{} & \multicolumn{5}{|c|}{ ANOVA } \\
\hline 1 & Model & Sum of squares & df & Mean square & F & Sig. \\
\hline & Regression & 309830.2 & 4 & 77457.544 & 1268.440 & .000 \\
\hline Residual & 49462.822 & 810 & 61.065 & & \\
\hline Total & 359293.0 & 814 & & & \\
\hline
\end{tabular}

three groups whereas a lack-of-fit test is nonsignificant, therefore we have no reason to question the adequacy of this order of models.

The statistical analysis is done by SPSS software application. Tables 11-13 show coefficients for these three groups of jobs. Based on these results (Tables 11 and 12) the factor effect of $X_{1}$ to $X_{4}$ is significant. We present results for statistical analysis of managerial and professional jobs by following first-order regression models.

Managerial knowledge based activity difficulty index (DI):

$\hat{y}=0.183 \mathrm{X}_{1}+0.35 \mathrm{X}_{2}+0.156 \mathrm{X}_{3}+0.271 \mathrm{X}_{4}$ 


\section{Table 11}

Determining coefficients for managerial knowledge based activities DI

\begin{tabular}{|c|c|c|c|c|c|c|}
\hline \multicolumn{7}{|c|}{ Coefficients } \\
\hline & \multirow[b]{2}{*}{ Model } & \multicolumn{2}{|c|}{$\begin{array}{l}\text { Unstandardized } \\
\text { coefficients }\end{array}$} & \multicolumn{2}{|c|}{$\begin{array}{l}\text { Standardized } \\
\text { coefficients }\end{array}$} & \multirow[b]{2}{*}{ Sig. } \\
\hline & & B & Std. Error & Beta & $\mathbf{t}$ & \\
\hline 1 & UNCERTAI & 1.108 & .091 & .183 & 12.124 & .000 \\
\hline & SKILL & 1.765 & .106 & .350 & 16.661 & .000 \\
\hline & VARIABLI & .771 & .116 & .156 & 6.627 & .000 \\
\hline & AMOUNT & 1.357 & .111 & .271 & 12.217 & .000 \\
\hline
\end{tabular}

Table 12

Determining coefficients for professional knowledge based activities DI

\begin{tabular}{|c|c|c|c|c|c|c|}
\hline \multicolumn{7}{|c|}{ Coefficients } \\
\hline & \multirow[b]{2}{*}{ Model } & \multicolumn{2}{|c|}{$\begin{array}{l}\text { Unstandardized } \\
\text { coefficients }\end{array}$} & \multicolumn{2}{|c|}{$\begin{array}{l}\text { Standardized } \\
\text { coefficients }\end{array}$} & \multirow[b]{2}{*}{ Sig. } \\
\hline & & B & Std. Error & Beta & $\mathbf{t}$ & \\
\hline 1 & UNCERTAI & 1.404 & .094 & .227 & 14.943 & .000 \\
\hline & SKILL & 2.277 & .108 & .441 & 21.074 & .000 \\
\hline & VARIABLI & .834 & .113 & .163 & 7.398 & .000 \\
\hline & AMOUNT & .624 & .104 & .120 & 5.985 & .000 \\
\hline
\end{tabular}

Professional knowledge based activity difficulty index (DI):

$\hat{y}=0.227 \mathrm{X}_{1}+0.441 \mathrm{X}_{2}+0.163 \mathrm{X}_{3}+0.12 \mathrm{X}_{4}$

However, as Table 13 shows, the main factor effects of clerical knowledge based activities DI for X2 to X4 are significant while X1 is not significant. DI for clerical jobs can be presented by formula (5).
Clerical knowledge based activity difficulty index (DI):

$\hat{y}=0.025 \mathrm{X}_{1}+0.552 \mathrm{X}_{2}+0.177 \mathrm{X}_{3}+0.19 \mathrm{X}_{4}$ (5) We can justify these results as clerical jobs are usually specified and then uncertainty has a low effect on the difficulty index for this group of jobs.

Table 13

Determining coefficients for clerical knowledge based activities DI

\begin{tabular}{|c|c|c|c|c|c|c|}
\hline \multicolumn{7}{|c|}{ Coefficients } \\
\hline & \multirow[b]{2}{*}{ Model } & \multicolumn{2}{|c|}{$\begin{array}{l}\text { Unstandardized } \\
\text { coefficients }\end{array}$} & \multicolumn{2}{|c|}{$\begin{array}{l}\text { Standardized } \\
\text { coefficients }\end{array}$} & \multirow[b]{2}{*}{ Sig. } \\
\hline & & B & Std. Error & Beta & $t$ & \\
\hline 1 & UNCERTAI & .156 & .157 & .025 & .994 & .320 \\
\hline & SKILL & 2.691 & .234 & .552 & 11.523 & .000 \\
\hline & VARIABLI & .882 & .270 & .177 & 3.267 & .000 \\
\hline & AMOUNT & .951 & .247 & .190 & 3.851 & .000 \\
\hline
\end{tabular}

\section{1}

\section{Analysis and applications}

We now analyse the results that were obtained in the previous section. As Tables 11-13 show, the main factor for determining the difficulty index of KBAs in all three groups is Level of skill and expertise needed for performing this type of activity. This means that most tasks of these three groups of workers require expertise and skill for performing them, and this parameter has the main effect on the difficulty of their job. This result is appropriate within our definition of knowledge work.

However, the amount of information that must be analysed in managerial tasks is more extensive than in professional jobs, and this parameter has a secondary effect on the 
difficulty of managerial jobs; the secondary effect in professional jobs is the uncertainty factor.

On the other hand, based on the results that are presented in Table 13, the amount of information has a secondary effect on the difficulty index for clerical jobs, and this means that clerical staff must gain more information than is needed by managers, because they have to cooperate and interact with managers.

In addition, with respect to the results that are presented in Table 12, variability of information has more effect in professional jobs than in the jobs of managers and clerks. This can be justified according to their innovative and designing activities.

As mentioned before, the main characteristic of knowledge work is quality, and difficulty is the important index of quality (Drucker, 1999). Exploring the process difficulty of the knowledge work is a potential way to improve the performance of this work (Cao \& Li, 2008:1).

On the other hand, managers need different methods, theories, and measures to manage the performance of KWrs who belong to different categories (Heidary et al., 2011). Three major factors (management and Organisation, information technology and workplace design) influence the performance of knowledge workers and knowledge-based Organisations (Davenport, 2002; 2005). Difficulty index of KBAs that defined in this article can be used for planning appropriate managerial solutions and selecting suitable IT solutions for different groups of knowledge workers.

Difficulty index of KBAs can be used for redesigning HRM systems commensurate with the characteristics of knowledge workers. Some applications related to this target are:

(1) Precise identification of activities (and proportionally the knowledge, skills and abilities needed) which should be considered in recruitment of knowledge workers; (2) Identification of Knowledge domains that must be considered in knowledge workers' training need assessment; (3) Redesigning complex and difficult jobs with respect to difficulty of different tasks and activities that comprised the job; (4) Give consideration to difficulty index in payroll system (especially in reward system and performance evaluation coefficients).

In addition, factors identified for determining the difficulty index of KWs and their importance in each three categories of $\mathrm{KW}$, can be used as a guide for selecting appropriate IT solutions.

The main factor for determining the difficulty index of KBAs in all three groups is level of skill and expertise, and these means that appropriate knowledge management systems must be designed for each one of these groups. Uncertainty and variability of information are two main factors (after skill and expertise) in determining difficulty of professional works. Due to this, some solutions for finding up to date knowledge and using their colleagues' experience are very important for these group of KWrs (like: knowledge bases and effective communication tools).

In managerial work, after skill and expertise, the other three factors have an important role in determining the difficulty index. Therefore, they need technologies that can summarise large amounts of data and information and help them in decision-making process (like: DSS Systems). In clerical work, the amount and variability of information are major factors (after skill and expertise). Then, enhancing the speed and accuracy in this category of KW needs process application and work flow to routinise the work.

\section{2}

\section{Conclusions and future work}

The current work focuses on determining the factors influencing the difficulty of knowledge based activities (KBAs), and comparing these factors for three groups of knowledge workers: managers, professionals and clerks. These factors are variability of information, amount of information, uncertainty and level of skill and expertise. The difficulty index of KBAs was defined, and regression models were developed based on empirical data that had been collected. These factors can be used for redesigning HRM systems commensurate with the characteristics of knowledge workers and as a guide for selecting appropriate IT solutions.

This work can be continued by applying it to more empirical studies and more jobs. Other multivariate data analysis methods (like canonical analysis) can be used for evaluating the results of this article. Also, more effort will be required to design systems tailored to each of the applications introduced in this article. 


\section{Acknowledgement}

The authors would like to thank Mr Attarian, Mr Madani and Mr Blight for their help with this research. Although taking responsibility for any of the remaining errors, the authors would like to thank two anonymous reviewers for a number of comments that have greatly improved our article.

\section{References}

BRANNICK, M.T. \& LEVINE, E.L. 2002. Job analysis: methods, research, and applications for human resource management in the new millennium. Thousand Oaks, CA: Sage.

CAO, H. \& LI, Y. 2008. The empirical study of the process difficulty of knowledge work. Wireless Communications, Networking and Mobile Computing (WiCOM '08), IEEE .1-4.

COATES, J. 1986. Three models for white collar productivity improvement. Industrial Management, 28(2): 7-14.

CORTADA, J.W. 1998. Rise of the knowledge worker. Boston, MA: Butterworth-Heinemann.

DAVENPORT, T. 2002. Can you boost knowledge worker's impact on the bottom line? Management Update, 7(11):3-5.

DAVENPORT, T. 2005. Thinking for a living: how to get better performance and results from knowledge workers. Boston MA: Harvard Business School Press.

DAVENPORT, T.H., THOMAS, R.J., CANTRELL, S. 2002. The mysterious art and science of knowledgeworker performance. MIT Sloan Management Review, 44(1):23-30

DAVIS, G.B. 2001. An emerging issue: knowledge worker productivity and information technology. Informing Science Conference, Available at: http://informingscience.org/proceedings/ IS2001Proceedings/Overheads/Davis\%20KrakowTalkKnowledgeWork.ppt.

DAVIS, G.B. 2002. Anytime/anyplace computing and the future of knowledge work. Communications of the $A C M, 45(12): 67-73$

DOVE, R. 1998. The knowledge worker. Automotive Manufacturing and Production, 110(6):26-8.

DRUCKER, P.F. 1959. The landmark of tomorrow. New York: Harper \& Row.

DRUCKER, P.F. 1993. Post-capitalist society. New York: Harper \& Row.

DRUCKER, P.F. 1999. Knowledge worker productivity: the biggest challenge. California Management Review, 419(2):79-94.

FINE, S.A., HARVEY, R.J. \& CRONSHAW, S.F. 2004. FJA strategies for addressing O*NET limitations in a post-DOT environment, in Fleishman, E.A. (Chair), Things, data, and people: fifty years of a seminal theory. Proceedings of the 19th annual conference of the Society for Industrial and Organizational Psychology; Chicago. Available at: http://www.siop.org/Conferences/04Con/Program/saturday_am.aspx [accessed July 2010].

FRANCALANCI, C. \& GALAL, H. 1998. Information technology and worker composition: determinants of productivity in the life insurance industry. MIS Quarterly, 22(2):227-41.

GRADY, C.L., HORWITZ, B., PIETRINI, P., MENTIS, M., UNGERLEIDER, L.G., RAPOPORT, S. \& HAXBY, J.V. 1996. Effect of task difficulty on cerebral blood flow during perceptual matching of faces. Human Brain Mapping, 4(4):227-239.

GUNS, W.D. \& VALIKANGAS, L. 1998. Rethinking knowledge work: creating value through idiosyncratic knowledge. Journal of Knowledge Management, 1(4):287-93.

HAMMER, M., LEONARD, D. \& DAVENPORT, T. 2004. Why don't we know more about knowledge? MIT Sloan Management Review, 45(4):4-18.

HAMPSON, I. \& JUNOR, A. 2005. Invisible skills: interactive customer service as articulation work. New Technology, Work and Employment, 20(2):166-181.

HARKINS, S.G. \& PETTY, R.E. 1982. Effects of task difficulty and task uniqueness on social loafing. Journal of Personality and Social Psychology, 43(6):1214-1229.

HASHEMIAN, N. \& AFRAZEH, A. 2006. Using information for classification of knowledge works. IEEE 2nd ICTTA, Syria.

HEIDARY DAHOOIE, J., AFRAZEH, A. \& MOATTAR HOSSEINI. 2011. An activity based framework for quantification of knowledge work. Journal of Knowledge Management, 15(3):422-444. 
HUBER, V.L. 1985. Effects of task difficulty, goal setting, and strategy on performance of a heuristic task. Journal of Applied Psychology, 70(3):492-504.

IIVARI, J. \& LINGER, H. 1999. Knowledge work as collaborative work: a situated activity theory view. Proceedings of the Hawaiian International Conference on Systems Science (HICSS'32):1-10.

JACKSON, D.F. 1989. A methodology for the quantification of knowledge work, PHD Thesis, University of Tennessee.

LAVOIE, M., ROY, R. \& THERRIEN, P. 2002. A growing trend toward knowledge work in Canada. Research Policy, 31(8):1-18.

LEE, C. 2005. Perceived job change toward dimensions of knowledge work among three levels of employees in a Korean bank, $\mathrm{PhD}$ Thesis, School of The Ohio State University.

LEIGH, J.W. 1984. Management in the nineties: Office technology and the knowledge worker, M.S. thesis. MUNDEL, M.E. 1983. Wanted: a system that provides box scores for productivity. Industrial Engineering, October 1983:74-81.

National Center for O*NET Development (2010), O*NET content model. Available at: http://www.onetcenter.org/dl_files/ContentModel_DetailedDesc.pdf [accessed 2009].

NICKOLS, F. 2000. What is in the world of work and working: some implications of the shift to knowledge work. Butterworth-Heinemann Yearbook of Knowledge Management:1-7.

NORTON, R. 2003. DACUM: Developing a curriculum workshop. Columbus. Center on education and training for employment, The Ohio State Univesrity.

OKKONEN, J. 2003. The use of performance measurement in knowledge work context, $\mathrm{PhD}$ Thesis, Tampere University of Technology.

PAN, W., LIU, J. \& HAWRYSZKIEWYCZ, I. 2008. A method for describing knowledge work processes. International Workshop on Advanced Information Systems for Enterprises (iwaise):46-52.

PHILIASTIDES, M.G., RATCLIFF, R. \& SAJDA, P. 2006. Neural representation of task difficulty and decision making during perceptual categorization: a timing diagram. Journal of Neuroscience, 26(35): 8965-8975.

PYORIA, P. 2005. The concept of knowledge work revisited. Journal of Knowledge Management, 9(3): 116-127.

RAMIREZ, Y.W. \& STEUDEL, H.J. 2008. Measuring knowledge work: the knowledge work quantification framework. Journal of Intellectual Capital, 9(4):564-584.

SHI-YOU, Q.U.v2008. Knowledge characteristics of Jobs and the empirical test. International Conference on Management Science \& Engineering (15th):1010-1017.

THOMAS, B.E. \& BARON, J.P. 1994. Evaluating knowledge worker productivity: literature review. Interim Report, FF-94/27, USACERL:1-27. Available at: www.cecer.army.mil/kws/tho_lit.htm\#abs

TURNER, T. \& D'ART, D. 2008. Is there a new knowledge economy in Ireland? An analysis of recent occupational trends. International Journal of Manpower, 29(8):700-714.

VELTMAN, J.A. \& GAILLARD, W.K. 1998. Physiological workload reactions to increasing levels of task difficulty. Ergonomics, 41(5):656-669. 


\section{Appendix 1: Defining knowledge work activities based on $\mathrm{O}$ *net and matching them with literature}

\begin{tabular}{|c|c|}
\hline O*net general activities & Literature knowledge processes \\
\hline Information Input & Knowledge activities \\
\hline Looking for and receiving job-related information & Find \\
\hline - Getting information & \\
\hline - $\quad$ Monitoring processes, materials, or surroundings & \\
\hline - Identifying and evaluating job-relevant information & Find \\
\hline - Identifying objects, actions, and events & \\
\hline - Inspecting equipment, structures, or material & \\
\hline - Estimating the quantifiable characteristics of products, events, or information & \\
\hline Mental Processes & Knowledge activities \\
\hline Information and data processing & Analyse \& process \\
\hline - Judging the qualities of things, services, or people & \\
\hline - Processing information & \\
\hline - $\quad$ Evaluating information to determine compliance with standards & \\
\hline - Analysing data or information & \\
\hline Reasoning and decision making & $\begin{array}{l}\text { Apply, transform, create, develop, } \\
\text { synthesise, brain process, create new } \\
\text { things, decide, plan, solve problem }\end{array}$ \\
\hline - Making decisions and solving problems & \\
\hline - $\quad$ Thinking creatively & \\
\hline - $\quad$ Updating and using relevant knowledge & \\
\hline - $\quad$ Developing objectives and strategies & \\
\hline - Scheduling work and activities & \\
\hline - Organizing, planning, and Prioritising work & \\
\hline
\end{tabular}

